\title{
On-line determination of ammonia at low pptv mixing ratios in the CLOUD chamber
}

\author{
F. Bianchi ${ }^{1}$, J. Dommen ${ }^{1}$, S. Mathot ${ }^{2}$, and U. Baltensperger ${ }^{1}$ \\ ${ }^{1}$ Laboratory of Atmospheric Chemistry, Paul Scherrer Institute, Villigen, Switzerland \\ ${ }^{2}$ CERN, Genève, Switzerland
}

Correspondence to: J. Dommen (josef.dommen@psi.ch)

Received: 1 February 2012 - Published in Atmos. Meas. Tech. Discuss.: 6 March 2012

Revised: 14 June 2012 - Accepted: 16 June 2012 - Published: 19 July 2012

\begin{abstract}
A new instrument for the on-line determination of ammonia was developed. Since ammonia is a rather sticky compound, sampling losses were minimised with a new sampling device where the ammonia was transferred to the liquid phase only $5 \mathrm{~mm}$ after the inlet tip. The liquid phase was then analyzed by long pathlength absorption spectrophotometry using the Berthelot reaction with phenol and hypochlorite as reagents. The measurements were made during the CLOUD3 campaign at CERN where the influence of ammonia on the nucleation rate was studied. At stable conditions the detection limit reached with this instrument was $35 \mathrm{pptv}$ (air flow rate of $21 \mathrm{~min}^{-1}$, liquid flow rate of $0.3 \mathrm{ml} \mathrm{min}^{-1}$ ), although occasionally the instrument was affected by background problems. The range of mixing ratios during this campaign was varied from the background contamination $(<35$ pptv) up to around 2 ppbv. The measured ammonia concentration was correlated with the rate of ammonia injected into the chamber, but with a response time of several hours due to the high tendency of ammonia to adsorb to or to desorb from surfaces. Since it was found that ammonia strongly increases the nucleation rate already at the lowest measured concentration, future work will focus on further decreasing the detection limit of the instrument.
\end{abstract}

\section{Introduction}

Ammonia is a ubiquitous compound in the atmosphere and it plays an important role in atmospheric chemistry due to the fact that it is the most abundant base in the atmosphere's gas phase. It rapidly reacts with acids and in this way contributes to aerosol mass, e.g. by forming ammonium sulfate with sulphuric acid or ammonium nitrate with nitric acid. Moreover, it is well known that ammonia enhances the nucleation of new particles through ternary homogeneous nucleation (THN) of $\mathrm{H}_{2} \mathrm{SO}_{4}-\mathrm{NH}_{3}-\mathrm{H}_{2} \mathrm{O}$ (Coffman and Hegg, 1995; Ball et al., 1999; Korhonen et al., 1999; Benson et al., 2011; Kirkby et al., 2011). Therefore, ammonia is expected to enhance the nucleation rate already at very low concentrations. However, there are conflicting results on the actual magnitude of this enhancement. For example, Korhonen et al. (1999) presented model results predicting an increase of the nucleation rate by several orders of magnitude for mixing ratios exceeding 1 pptv of $\mathrm{NH}_{3}$. Ball et al. (1999) reported laboratory studies where several tens of pptv of added ammonia increased the nucleation rate by orders of magnitude. On the other hand, Benson et al. (2011) found only a small enhancement factor $(<10)$ in the nucleation rate after ammonia addition. In their experiment the ammonia concentration was between 0.08 and $20 \mathrm{ppbv}$ and the sulphuric acid concentration was $10^{6}-10^{7} \mathrm{~cm}^{-3}$. Therefore, more studies on the influence of $\mathrm{NH}_{3}$ on the nucleation rate at ambient concentrations of sulphuric acid are needed, especially where ammonia mixing ratios are in the low pptv range.

Due to the importance of this compound, its concentration has been measured at many places in the field and several instrument intercomparisons have been reported. Fehsenfeld et al. (2002) performed an intercomparison of ammonia measurement techniques between chemical ionisation mass spectrometry (CIMS), citric acid denuder technique and a molybdenum-oxide converter-difference (MoOx-CD) technique in the field. Quite good agreement was found, especially between CIMS and the citric acid denuder. Schwab et al. (2007) performed a laboratory intercomparison of seven 
real-time instruments for gaseous ammonia measurement using six different methods. Two out of these used aqueous scrubbing of ammonia which is detected after chemical conversion by either long pathlength absorption photometry or fluorescence spectroscopy. The other methods measured ammonia directly by either tunable diode laser absorption spectroscopy, laser photoacoustic spectroscopy, ion mobility spectrometry or after catalytic conversion by chemiluminescence. Detection limits from 25-200 pptv were reported in their study of the different instruments, which generally agreed to within about $25 \%$ (Schwab et al., 2007). Emmenegger et al. (2004) made an intercomparison in a tunnel with seven different instruments at relatively high concentrations. Von Bobrutzki et al. (2010) compared eleven instruments based on eight different methods in the field. Three instruments were wet-chemistry systems while the other techniques used optical, photo-acoustic and mass spectrometric techniques. A high correlation was found $\left(R^{2}>0.84\right)$ for the average of all the instruments at higher concentrations but more variability was found at concentrations below 12 ppbv. Recently, CIMS has increasingly been used for the determination of ammonia in the atmosphere. The advantage of such an instrument is the high time resolution and the fast response, but the high variability in the background does not allow yet for low detection limits (Normann et al., 2009; Nowak et al., 2007, 2010; Benson et al., 2010; von Bobrutzki et al., 2010; Hanson et al., 2011). Despite all efforts, the determination of ammonia at low concentrations remains difficult.

Besides the low detection limits required, the determination of ammonia is difficult for several additional reasons. First, ammonia partitions between the gas and aerosol phase. Gaseous ammonia must therefore be separated from the particulate ammonium. Second, ammonia adsorbs on any kind of surfaces (Yokelson et al., 2003). This phenomenon is the result of the strong hydrogen bond formed between water and ammonia. For this reason it is catalogued as a "sticky" compound. Third, ammonia has a relatively high diffusion coefficient: $0.1978 \mathrm{~cm}^{2} \mathrm{~s}^{-1}$ at $273.15 \mathrm{~K}$ (Massman, 1998). The combination of the last two properties can cause huge losses and a slow response time in the inlet line. Consequently, special care needs to be taken regarding design and choice of material to minimise these difficulties in the sampling (Fehsenfeld et al., 2002; Bae et al., 2007; Benson et al., 2010; von Bobrutzki et al., 2010).

In this paper we describe a method for ammonia measurements at mixing ratios in the low pptv range that was developed in the context of the CLOUD experiments at CERN. Within this project the nucleation of new particles caused by sulphuric acid, ammonia and other vapors is investigated under well controlled conditions (Kirkby et al., 2011). The CLOUD3 experiments performed in October 2010 aimed at investigating the influence of ammonia at pptv levels on the nucleation rate of gaseous sulphuric acid/water mixtures. In these experiments no preexisting aerosol with a

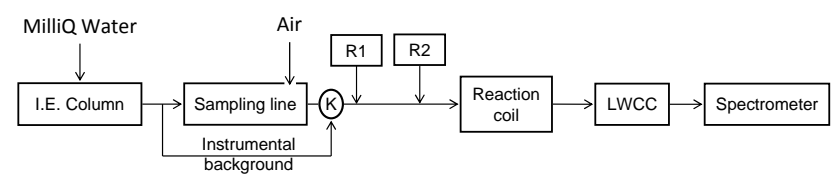

Fig. 1. Scheme of the instrument: R1 and R2 denote the phenol+ nitroprusside and hypochlorite respectively. LWCC: Liquid Waveguide Capillary Cell. The instrumental background is taken by measuring clean water, by-passing the sampling line. The valve $K$ is where the standard solutions were injected.

corresponding ammonium concentration was present, such that no separation between gaseous ammonia and particulate ammonium was required. To minimise the sampling losses, a new design of a sampling line was developed where ammonia was transferred to an aqueous solution at an early stage of the sampling. In this way we were able to determine gas phase ammonia mixing ratios at low pptv levels with a good time resolution using long pathlength absorption photometry.

\section{Experimental}

\subsection{Measurement principle}

The technique used here is based on a colorimetric reaction called Berthelot reaction where ammonia reacts with sodium hypochlorite and phenol to yield indophenol; in alkaline solution, this compound is blue and absorbs light at $640 \mathrm{~nm}$ (Patton and Crouch, 1977). This highly specific and extremely sensitive reaction occurs in two steps. First, ammonia reacts with hypochlorite to form mono-chloramines. Second, the phenol reacts with chloramines to give indophenol. To increase the reaction rate, a catalyst is added; in our case this catalyst is sodium nitroprusside dehydrate. To increase the sensitivity we used long pathlength absorption photometry based on the liquid-waveguide capillary cell (LWCC) technology (Heland et al., 2001; Dallas and Dasgupta, 2004; Li et al., 2005; Schwab et al., 2007; Toda and Dasgupta, 2008). This method is increasingly used for trace gas analysis.

\subsection{Apparatus}

A simplified scheme of the apparatus is shown in Fig. 1. Ultrapure water (MilliQ SUPER - QTM PLUS, resistivity of $18.3 \mathrm{M} \Omega \mathrm{cm}$ ) is further cleaned with an ion exchange (I.E.) column (IONPAC CTC-1 cation trap column from Dionex) before being fed into the sampling line. There, ammonia is stripped from the gas phase into the water flow rate, which then enters the instrument. The reagents (phenol + nitroprusside as well as hypochlorite) are then added at positions R1 and R2, respectively. The reaction between the reagents and ammonia takes place in a reaction coil (Teflon tubing) of $6 \mathrm{~m}$ length (residence/reaction time of $540 \mathrm{~s}$ ). This 
length is a good compromise between sensitivity, time delay of signal appearance and reproducibility. The blue indophenol solution is then pumped into a liquid-waveguide capillary cell (World Precision Instrument) with an optical length of $5 \mathrm{~m}$. The inner surface is coated with fused silica. The LWCC is coupled with a red light-emitting diode (LED, with the mode at $638 \mathrm{~nm}$ ) through an optical fiber. The light transmitted through the LWCC is detected by a spectrometer (USB 2000 from Ocean Optics). Due to the reaction time the appearance of the signal is delayed by $540 \mathrm{~s}$. The time response of the instrument is mainly influenced by the mixing in the reaction coil and the length of the LWCC. The instrumental time response defined as the rise time of a step concentration change (from $10 \%$ to $90 \%$ of its final value) was measured to be $10 \mathrm{~min}$.

Reagents 1 and 2 were prepared with water from the same MilliQ system. Reagent 1 was prepared dissolving $20 \mathrm{~g}$ of phenol (puriss. 99.5\%, Sigma-Aldrich) and $0.9 \mathrm{~g}$ of sodium nitroprusside dehydrate ( $99 \%$, Sigma Aldrich) in one liter of a $0.5 \mathrm{moll}^{-1}$ sodium hydroxide solution. Reagent 2 was prepared with $30 \mathrm{ml}$ of sodium hypochlorite (Sigma Aldrich) and $30 \mathrm{ml}$ of sodium hydroxide $1 \mathrm{moll}^{-1}$ (Fluka) in a 11 solution. During first tests we noted that particles were formed, presumably from degradation of the catalyst in the basic solution. These particles produced light scattering in the LWCC, inducing a baseline drift in the instrument signal. This problem was minimised by introducing an in-line particle filter with a pore size of $2 \mu \mathrm{m}$ just before the LWCC. The reagents were stored in compressible plastic bags in a dark box to avoid the introduction of ambient air and therefore to minimise contamination and aging of the reagents, since they are sensitive to both air and light. In addition, the solutions were changed daily.

Calibration was performed with different concentrations of $\mathrm{NH}_{4} \mathrm{Cl}$. Standard solutions with concentrations of 0,50 , 100,200 , and $400 \mathrm{nmol}^{-1}$ were produced by diluting a pure $\mathrm{NH}_{4}^{+}$standard solution (Fluka, $0.010 \mathrm{nmol} \mathrm{l}^{-1}$ ).

\subsection{Ammonia sampling}

Ammonia is a rather sticky compound and is quite difficult to sample, as discussed above. In addition, the standard sampling lines at the CLOUD chamber are $130 \mathrm{~cm}$ long and half-inch $(12.7 \mathrm{~mm})$ diameter stainless steel tubes. Taking for example a high flow rate of $101 \mathrm{~min}^{-1}$ would translate into a penetration efficiency of only $11 \%$ using the Gormley-Kennedy equation (Willeke and Baron, 1993), and a diffusion coefficient of $0.2234 \mathrm{~cm}^{2} \mathrm{~s}^{-1}$ at $273 \mathrm{~K}$ (Massman, 1998). To minimise these losses and to improve the collection efficiency, a special sampling system was developed (Fig. 2). The design is based on the fact that ammonia is easily taken up by water (Toda and Dasgupta, 2008).

A stainless steel tube of $34 \mathrm{~mm}$ outer diameter penetrates $50 \mathrm{~cm}$ into the CLOUD chamber and is closed at the front end. From a small opening ( $2 \mathrm{~mm}$ diameter) on top close to

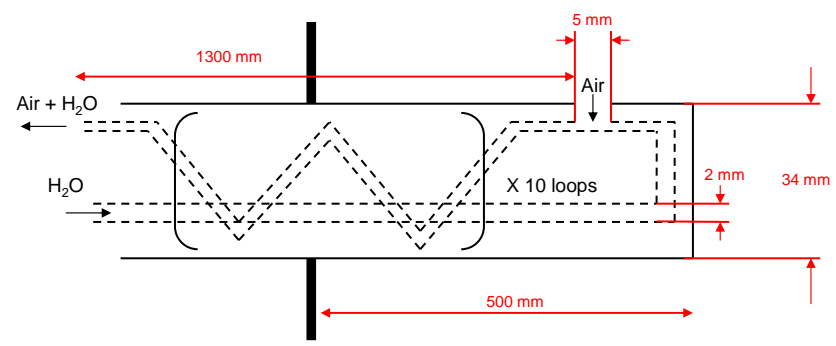

Fig. 2. Sketch of the sampling line not scaled. The thick bars indicate the CLOUD chamber wall. Red color gives the dimensions of the sampling line.

the front end, air is aspirated to the scrubbing tube (stainless steel, $2 \mathrm{~mm}$ inner diameter) inside this large tube. Water is fed through this tube to the sampling port and the air/water mixture is then transported out via 10 coils to enhance the residence time to a debubbler where the gas and liquid phase are separated. The liquid flow rate is $0.3 \mathrm{ml} \mathrm{min}^{-1}$ and the gas flow rate $21 \mathrm{~min}^{-1}$, resulting in an ammonia residence time lower than one second between sampling and debubbler.

Due to the geometry of the sampling line, this instrument measures both gas and particle phase. However, since we observe only the nucleation period of tiny particles, the contribution of ammonia from the particle phase can be considered negligible.

\subsection{Measurements}

From Lambert-Beer's law we know that the concentration of the indophenol, and therefore of ammonia, is proportional to the absorbance of the solution. Due to the baseline drift problem, we do not report data from continuous measurements of ammonia in the chamber even though we were using the online instrument that provided data every $2 \mathrm{~s}$ (acquisition time of the UV-Vis spectrometer). Rather, the reported ammonia concentrations are the difference between the measurement of the CLOUD chamber concentration and the instrument background which was taken regularly. The latter is the measurement of the ultrapure water bypassing the sampling line and entering directly the instrument.

\subsection{CLOUD chamber}

As mentioned before, this instrument was applied during the CLOUD experiment at CERN (Kirkby et al., 2011; Kupc et al., 2011; Voigtländer et al., 2012). This chamber is a 3-m diameter electropolished stainless-steel cylinder of $26.1 \mathrm{~m}^{3}$. To stimulate photolytic reactions the contents of the chamber are irradiated by ultra violet (UV) light in the range 250 $400 \mathrm{~nm}$. The chamber temperature is controlled by precisely regulating the temperature of the air circulating in the space between the chamber and its surrounding thermal housing; the temperature stability of the chamber is around $\pm 0.01 \mathrm{~K}$, with no observable change when the UV lights are turned 


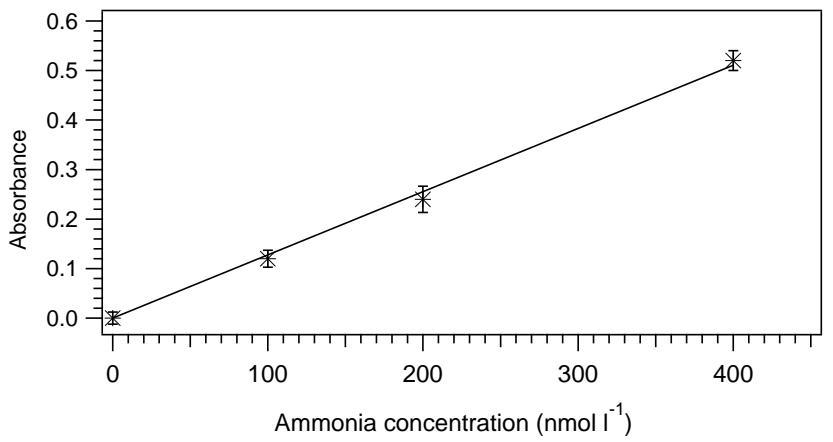

Fig. 3. Calibration of the instrument using solutions with different ammonia concentrations. The error bars represent one standard deviation. The fit is forced through the origin.

on at full power. In addition, the chamber can be raised to $373 \mathrm{~K}$ for cleaning. The nominal operating pressure is one atmosphere. Pure air, free of condensable vapors, is obtained from the evaporation of cryogenic liquid $\mathrm{N}_{2}$ and liquid $\mathrm{O}_{2}$, mixed in the ratio $79: 21$, respectively. Trace gases such as $\mathrm{SO}_{2}$ or $\mathrm{NH}_{3}$ are obtained from gas cylinders containing 100 ppmv and $1 \%$ concentrations, respectively, in pressurized $\mathrm{N}_{2}$. Each trace gas is diluted with air to the required concentration before entering the chamber, and has an individual circuit, with an isolation valve at the chamber, to avoid cross-contamination or reactions with other gases outside the chamber. To avoid contamination from plastic materials, all gas piping is made from stainless steel, and all gas and chamber seals are metal (gold-coated to render them chemically inert).

Two stainless steel fans are mounted inside the chamber, and coupled magnetically to flexible drives connected to motors located outside the thermal housing. The fans produce a counter-flow inside the chamber in order to rapidly mix the fresh gases.

\section{Results}

\subsection{Calibration and detection limit}

Figure 3 shows a calibration performed with $\mathrm{NH}_{4} \mathrm{Cl}$ solutions that were added at valve $K$. The instrument's response is linear at least up to $400 \mathrm{nmol}^{-1}$ and yields the following equation:

$\mathrm{ABS}=\left(0.0013 \pm 2.4 \times 10^{-5}\right)\left[\mathrm{NH}_{4}^{+}\right]$,

where ABS stands for absorbance. The detection limit, calculated as 3 times the standard deviation of the noise of the blank signal averaged over ten minutes, is about $10 \mathrm{nmoll}^{-1}$ for a liquid solution. With an air sample flow rate of $21 \mathrm{~min}^{-1}$ and a liquid flow rate of $0.3 \mathrm{ml} \mathrm{min}^{-1}$, this translates into a mixing ratio of about $35 \mathrm{pptv}$ for the gas phase. The detection limit was sometimes increased due to instabilities in the

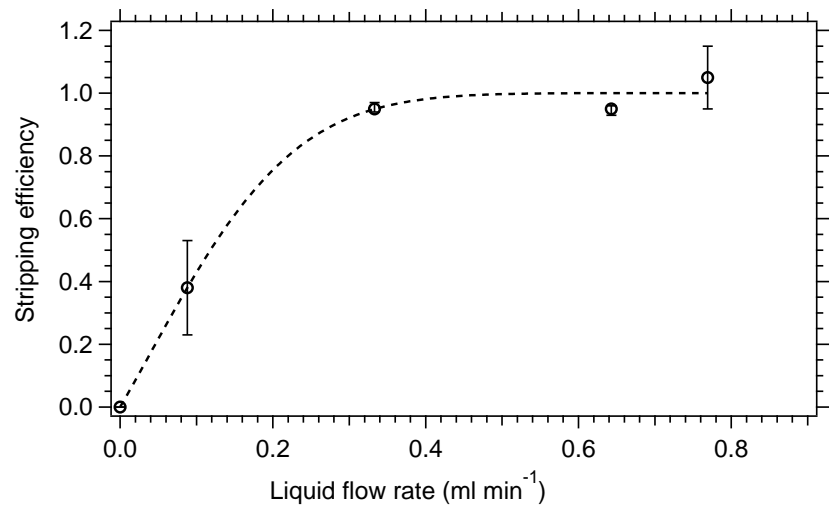

Fig. 4. Stripping efficiency versus liquid flow rate in the sampling line. Error bars represent 3 times the standard deviation of the measurements taken for each setting.

baseline associated with particle formation from the catalyst degradation.

The stripping efficiency of the sampling line, i.e. the fraction of gas phase ammonia collected per unit air sampled, was checked as follows: when the CLOUD chamber reached a constant concentration of ammonia, we varied the water flow rate keeping the air flow rate constant. The result is shown in Fig. 4. It is seen that, at a water flow rate greater than $0.3 \mathrm{ml} \mathrm{min}^{-1}$, the ammonia signal did not increase further, indicating that the stripping of ammonia is complete at this water flow rate.

\subsection{Ammonia mixing ratio in the CLOUD experiments}

With optimal cleaning and without intentional ammonia addition, the ammonia mixing ratio in the CLOUD chamber was below the detection limit of 35 pptv. Still, there was evidence that an ammonia contamination was present, as e.g. shown by the fact that the Atmospheric Pressure interface Time-of-Flight (APi-TOF) mass spectrometer showed the presence of ammonia in the nucleating clusters (Kirkby et al., 2011). This clearly shows the need for further improvement of the detection limits in measuring ammonia and other potential contaminants.

In the second part of the experiment, ammonia was added intentionally. Figure 5 gives an overview of the concentrations in these experiments. Data are averaged over $30 \mathrm{~min}$. The concentration drop at the end of the first day can be explained by the fact that the cylinder containing ammonia was changed. Thereafter a re-equilibration of the injection line was needed.

The mass flow controller (MFC) setting of the ammonia addition is also shown in Fig. 5. There is a clear relationship between the MFC setting and the ammonia concentration. However, it is also seen that the response of the ammonia concentration to an increase in the MFC setting was quite slow. This was true during the whole campaign, but 


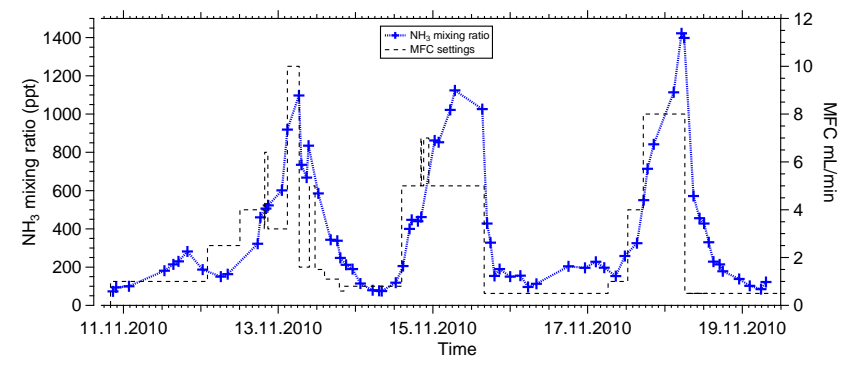

Fig. 5. Mass flow controller (MFC) settings of the ammonia inlet and the ammonia mixing ratio during the campaign.

especially pronounced on the first day of ammonia addition when no constant concentration was reached even after $24 \mathrm{~h}$ of a constant MFC setting. After a decrease of the MFC setting, the new steady state value was reached a bit faster (within about 3-6h) than after an increase. However, after stopping the ammonia addition completely later in the experiment, the initial background level of ammonia was not reached anymore even after $24 \mathrm{~h}$. Nevertheless, for those measurements where we can assume equilibrium, the estimated steady state concentration of ammonia in the chamber calculated from the injection flow and a wall loss lifetime of 15 min was in fairly good agreement with the measurement.

This behaviour can be partially explained by the properties of ammonia. This compound is sticky and has a high diffusion coefficient, which leads to fast losses to any walls. At the same time, ammonia is also evaporating back from the walls of the chamber and the inlet lines. Therefore, long times are needed to condition the inlet line, and it is difficult to reach the steady state quickly. Furthermore, every time the MFC was changed the whole injection line had to re-equilibrate again; when the MFC was set to a low level, the evaporation from the chamber wall continued for a long time until a new equilibrium was reached. These characteristics of ammonia underline once again the importance of the sampling directly into a liquid with a minimum transport time in the gas phase.

\subsection{Determination of the nucleation rate at different ammonia concentrations}

The results of this experiment are shown in Kirkby et al. (2011). Here, we just report an example of the dependence of the nucleation rate on the ammonia concentration. Nucleation rates $\left(J, \mathrm{~cm}^{-3} \mathrm{~s}^{-1}\right)$ were measured under neutral (using an internal electric clearing field), galactic cosmic rays and charged pion beam conditions, corresponding to ion-pair concentrations of about 0,400 and $3000 \mathrm{~cm}^{-3}$, respectively. Figure 6 shows the measured nucleation rate for a varying ammonia concentration at a fixed sulphuric acid concentration. The nucleation rates are seen to be highly sensitive to small additions of ammonia. When increasing the ammonia concentration from contamination level ( $<35 \mathrm{pptv})$ to about $100 \mathrm{pptv}$, both the neutral and ion-induced nucleation rates

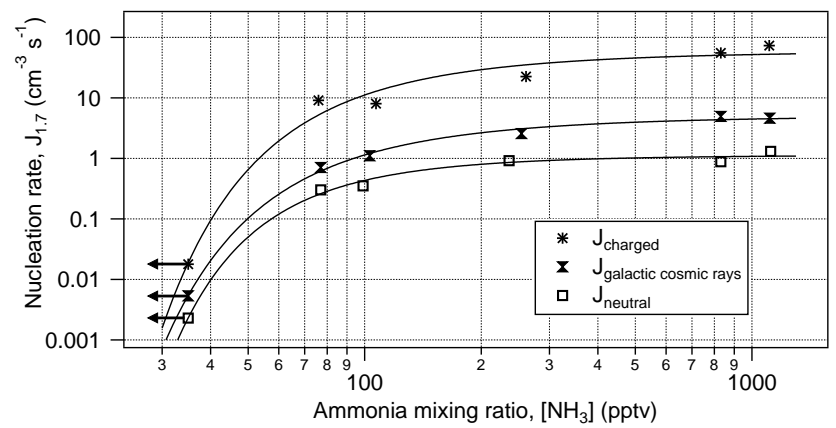

Fig. 6. Nucleation rates as a function of ammonia concentration at $292 \mathrm{~K}$ and $\left[\mathrm{H}_{2} \mathrm{SO}_{4}\right]=1.2 \times 10^{8} \mathrm{~cm}^{-3}$ (adapted from Kirkby et al., 2011). The curves are drawn to guide the eye. Experiments were performed under neutral, galactic cosmic rays and charged pion beam conditions, corresponding to ion-pair concentrations of about 0,400 and $3000 \mathrm{~cm}^{-3}$, respectively.

increased by about a factor of 100 . Above about 200 pptv the nucleation rates reached saturation. These observations provide direct experimental evidence that the nucleation rates are strongly limited by $\mathrm{NH}_{3}$ when its mixing ratio is below about 100 pptv.

These findings are quite different from previous studies. Benson et al. (2011) claimed that ammonia increased the nucleation rate by less than a factor of 10 . In their study the ratio between ammonia and sulphuric acid was much higher than in our study and in Kirkby et al. (2011). According to our findings, this indicates that their experiments were in a regime where the effect of $\mathrm{NH}_{3}$ on the nucleation rate was already partly saturated, and the response to a further increase of ammonia was strongly damped.

Note that the numbers in Fig. 6 relate to a sulphuric acid concentration of $1.2 \times 10^{8} \mathrm{~cm}^{-3}$. Based on the stepwise accretion of $\mathrm{NH}_{3}$ molecules shown in the charged cluster composition by the APi-TOF (Kirkby et al., 2011), it is to be expected that at a lower sulphuric acid concentration saturation is reached at an even lower $\mathrm{NH}_{3}$ mixing ratio. These results clearly call for reliable ammonia measurements well below 35 pptv.

\section{Conclusions}

We presented an on-line method to detect ammonia in the CLOUD chamber experiment at CERN. The method uses the Berthelot reaction to convert ammonia to indophenol which is detected through a spectrophotometric technique. A new sampling system using water was also developed to minimise sampling losses, which can be quite high for this compound. Under stable conditions a detection limit of $35 \mathrm{pptv}$ was reached.

In the CLOUD experiment, ammonia was injected to investigate the influence of this compound on the nucleation rate, with mixing ratios ranging from background levels up 
to $2 \mathrm{ppbv}$. The ammonia measurement and the setting of the mass flow controller governing the $\mathrm{NH}_{3}$ addition were well correlated, but after a change in the settings, several hours were needed to reach again a constant value. Due to the "stickiness" of ammonia it is quite difficult to accurately control the concentration of this gas.

Mixing ratios well below $100 \mathrm{pptv}$ showed a strong dependence on the nucleation rate, calling for even more sensitive methods for ammonia measurements in future studies.

Acknowledgements. We thank CERN for supporting CLOUD with important technical and financial resources, and for providing a particle beam from the CERN Proton Synchrotron. This work was supported by EC Seventh Framework Programme under grant agreement no. 215072 (Marie Curie Initial Training Network, "CLOUD-ITN") as well as the Swiss National Science Foundation.

Edited by: J. Abbatt

\section{References}

Bae, M. S., Demerjian, K. L., Schwab, J. J., Weimer, S., Hou, J., Zhou, X. L., Rhoads, K., and Orsini, D.: Intercomparison of real time ammonium measurements at urban and rural locations in New York, Aerosol Sci. Tech., 41, 329-341, 2007.

Ball, S. M., Hanson, D. R., Eisele, L., and McMurry, P. H.: Laboratory studies of particle nucleation: Initial results for $\mathrm{H}_{2} \mathrm{SO}_{4}, \mathrm{H}_{2} \mathrm{O}$ and $\mathrm{NH}_{3}$ vapors, J. Geophys. Res., 104, 23709-23718, 1999.

Benson, D. R., Markovich, A., Al-Refai, M., and Lee, S.-H.: A chemical ionization mass spectrometer for ambient measurements of ammonia, Atmos. Meas. Tech., 3, 1075-1087, doi:10.5194/amt-3-1075-2010, 2010.

Benson, D. R., Yu, J. H., Markovich, A., and Lee, S.-H.: Ternary homogeneous nucleation of $\mathrm{H}_{2} \mathrm{SO}_{4}, \mathrm{NH}_{3}$, and $\mathrm{H}_{2} \mathrm{O}$ under conditions relevant to the lower troposphere, Atmos. Chem. Phys., 11, 4755-4766, doi:10.5194/acp-11-4755-2011, 2011.

Coffman, D. J. and Hegg, D. A.: A preliminary study of the effect of ammonia on particle 25 nucleation in the marine boundary layer, J. Geophys. Res., 100, 7147-7160, 1995.

Dallas, T. and Dasgupta, P. K.: Light at the end of the tunnel: recent analytical applications of liquid-core waveguides, TracTrend Anal. Chem., 23, 385-392, 2004.

Emmenegger, L., Mohn, J., Sigrist, M., Marinov, D., Steinemann, U., Zumsteg, F., and Meier, M.: Measurement of ammonia emissions using various techniques in a comparative tunnel study, Int. J. Environ. Pollut., 22, 326-341, 2004.

Fehsenfeld, F. C., Huey, L. G., Leibrock, E., Dissly, R., Williams, E., Ryerson, T. B., Norton, R., Sueper, D. T., and Hartsell, B.: Results from an informal intercomparison of ammonia measurement techniques, J. Geophys. Res., 107, 4812, doi:10.1029/2001JD001327, 2002.

Hanson, D. R., McMurry, P. H., Jiang, J., Tanner, D., and Huey, L. G.: Ambient pressure proton transfer mass spectrometry: Detection of amines and ammonia, Environ. Sci. Technol., 45, 88818888, 2011.
Heland, J., Kleffmann, J., Kurtenbach, R., and Wiesen, P.: A new instrument to measure gaseous nitrous acid (HONO) in the atmosphere, Environ. Sci. Technol., 35, 3207-3212, 2001.

Kirkby, J., Curtius, J., Almeida, J., Dunne, E., Duplissy, J., Ehrhart, S., Franchin, A., Gagne, S., Ickes, L., Kurten, A., Kupc, A., Metzger, A., Riccobono, F., Rondo, L., Schobesberger, S., Tsagkogeorgas, G., Wimmer, D., Amorim, A., Bianchi, F., Breitenlechner, M., David, A., Dommen, J., Downard, A., Ehn, M., Flagan, R. C., Haider, S., Hansel, A., Hauser, D., Jud, W., Junninen, H., Kreissl, F., Kvashin, A., Laaksonen, A., Lehtipalo, K., Lima, J., Lovejoy, E. R., Makhmutov, V., Mathot, S., Mikkila, J., Minginette, P., Mogo, S., Nieminen, T., Onnela, A., Pereira, P., Petaja, T., Schnitzhofer, R., Seinfeld, J. H., Sipila, M., Stozhkov, Y., Stratmann, F., Tome, A., Vanhanen, J., Viisanen, Y., Vrtala, A., Wagner, P. E., Walther, H., Weingartner, E., Wex, H., Winkler, P. M., Carslaw, K. S., Worsnop, D. R., Baltensperger, U., and Kulmala, M.: Role of sulphuric acid, ammonia and galactic cosmic rays in atmospheric aerosol nucleation, Nature, 476, 429-433, 2011.

Korhonen, P., Kulmala, M., Laaksonen, A., Viisanen, Y., McGraw, R., and Seinfeld, J. H.: Ternary nucleation of $\mathrm{H}_{2} \mathrm{SO}_{4}, \mathrm{NH}_{3}$, and $\mathrm{H}_{2} \mathrm{O}$ in the atmosphere, J. Geophys. Res., 104, 26349-26353, 1999.

Kupc, A., Amorim, A., Curtius, J., Danielczok, A., Duplissy, J., Ehrhart, S., Walther, H., Ickes, L., Kirkby, J., Kurten, A., Lima, J. M., Mathot, S., Minginette, P., Onnela, A., Rondo, L., and Wagner, P. E.: A fibre-optic UV system for $\mathrm{H}_{2} \mathrm{SO}_{4}$ production in aerosol chambers causing minimal thermal effects, J. Aerosol Sci., 42, 532-543, 2011.

Li, Q. P., Zhang, J. Z., Millero, F. J., and Hansell, D. A.: Continuous colorimetric determination of trace ammonium in seawater with a long-path liquid waveguide capillary cell, Mar. Chem., 96, 73$85,2005$.

Massman, W. J.: A review of the molecular diffusivities of $\mathrm{H}_{2} \mathrm{O}$, $\mathrm{CO}_{2}, \mathrm{CH}_{4}, \mathrm{CO}, \mathrm{O}_{3}, \mathrm{SO}_{2}, \mathrm{NH}_{3}, \mathrm{~N}_{2} \mathrm{O}, \mathrm{NO}$, and $\mathrm{NO}_{2}$ in air, $\mathrm{O}_{2}$ and $\mathrm{N}_{2}$ near STP, Atmos. Environ., 32, 1111-1127, 1998.

Norman, M., Spirig, C., Wolff, V., Trebs, I., Flechard, C., Wisthaler, A., Schnitzhofer, R., Hansel, A., and Neftel, A.: Intercomparison of ammonia measurement techniques at an intensively managed grassland site (Oensingen, Switzerland), Atmos. Chem. Phys., 9, 2635-2645, doi:10.5194/acp-9-2635-2009, 2009.

Nowak, J. B., Neuman, J. A., Kozai, K., Huey, L. G., Tanner, D. J., Holloway, J. S., Ryerson, T. B., Frost, G. J., McKeen, S. A., and Fehsenfeld, F. C.: A chemical ionization mass spectrometry technique for airborne measurements of ammonia, J. Geophys. Res., 112, D10S02, doi:10.1029/2006JD007589, 2007.

Nowak, J. B., Neuman, J. A., Bahreini, R., Brock, C. A., Middlebrook, A. M., Wollny, A. G., Holloway, J. S., Peischl, J., Ryerson, T. B., and Fehsenfeld, F. C.: Airborne observations of ammonia and ammonium nitrate formation over Houston, Texas, J. Geophys. Res., 115, D22304, doi:10.1029/2010JD014195, 2010.

Patton, C. J. and Crouch, S. R.: Spectrophotometric and kinetics investigation of the Berthelot reaction for the determination of ammonia, Anal. Chem., 49, 464-469, 1977.

Schwab, J. J., Li, Y. Q., Bae, M. S., Demerjian, K. L., Hou, J., Zhou, X. L., Jensen, B., and Pryor, S. C.: A laboratory intercomparison of real-time gaseous ammonia measurement methods, Environ. Sci. Technol., 41, 8412-8419, 2007. 
Toda, K. and Dasgupta, P. K.: Environmental applications: Atmospheric trace gas analyses, Comprehensive Analytical Chemistry, volume 54, Elsevier, Amsterdam, The Netherlands, 639-683, 2008.

Voigtländer, J., Duplissy, J., Rondo, L., Kürten, A., and Stratmann, F.: Numerical simulations of mixing conditions and aerosol dynamics in the CERN CLOUD chamber, Atmos. Chem. Phys., 12, 2205-2214, doi:10.5194/acp-12-2205-2012, 2012.

von Bobrutzki, K., Braban, C. F., Famulari, D., Jones, S. K., Blackall, T., Smith, T. E. L., Blom, M., Coe, H., Gallagher, M., Ghalaieny, M., McGillen, M. R., Percival, C. J., Whitehead, J. D., Ellis, R., Murphy, J., Mohacsi, A., Pogany, A., Junninen, H., Rantanen, S., Sutton, M. A., and Nemitz, E.: Field inter-comparison of eleven atmospheric ammonia measurement techniques, Atmos. Meas. Tech., 3, 91-112, doi:10.5194/amt-3-91-2010, 2010.
Willeke, K. and Baron, P. A.: Aerosol Measurement: Principles, Techniques and Applications, Van Nostrand Reinhold Publishers, New York, 1993.

Yokelson, R. J., Christian, T. J., Bertschi, I. T., and Hao, W. M.: Evaluation of adsorption effects on measurements of ammonia, acetic acid, and methanol, J. Geophys. Res., 108, 4649, doi:10.1029/2003JD003549, 2003. 